\title{
Intencionalidade educativa em freqüência modulada: um desafio radiofônico
}

Lígia Beatriz Carvalho de Almeida

Mestra em Comunicação Midiática pela Universidade Estadual Paulista.

Professora da Universidade do Sagrado Coração.

E-mail: ligiabeatrizcarvalho@ig.com.br

Apresento algumas reflexões derivadas da experiência como coordenadora de programação de uma emissora de rádio educativa, na qual pude participar desde os primórdios, desenhando estratégias e objetivos. Nenhuma pretensão, no entanto, de estabelecer modelos teóricos advindos dessa práxis; move-nos, apenas, uma intenção dialógica. Para fundamentar nossas escolhas, no período em que estivemos na coordenação, posicionamos a emissora como parte do contexto midiático radiofônico regional no qual está inserida. Esse contexto faz com que a perseguição de objetivos educacionais, utilizando essa mídia, torne-se uma tarefa árdua, porém desafiadora.

As instituições que obtêm a gestão de emissoras educativas são, além da União Federal, Estados, Distrito Federal e os Municípios, as universidades brasileiras, públicas ou particulares. A legislação determina que a concessão seja delegada às instituições integradas aos sistemas de ensino de qualquer nível ou modalidade. Elas são incumbidas de prestar serviço de radiodifusão sonora veiculando programas educativo-culturais voltados para a educação básica e superior, para a educação permanente e formação para o trabalho. Devem promover atividades de divulgação educacional, cultural, pedagógica e de orientação profissional. Poderão veicular programas de caráter recreativo, informativo ou de divulgação desportiva, se neles estiverem presentes elementos instrutivos ou enfoques educativo-culturais identificados na sua apresentação ${ }^{1}$.

\section{COMO OPERAM AS EMISSORAS EDUCATIVAS}

Atualmente, tanto as universidades públicas como as privadas têm sido desafiadas a sobreviver com verbas cada vez mais reduzidas e também encontrado dificuldade, até mesmo, para manter a qualidade de ensino. Por isso, as

1. Para mais referências, podem ser consulta das as Leis n. 4.117, de 27/8/1962, e n. 9.637, de 15/5/1998 (art. 19); o Decreto-Lei n. 236, de 28/2/1967 (arts. 13-15), e a Portaria Interministerial n. 651 , de 15/4/1999. 
emissoras educativas, sob sua responsabilidade, operam com uma quantidade ínfima de profissionais.

Sem desfrutar de condições ideais para planejamento e produção de programas e, considerando-se sua inserção no universo acadêmico, a alternativa encontrada é voltar-se para a própria comunidade acadêmica; conseqüentemente, a grade de programação dessas emissoras acaba, na maior parte das vezes, apresentando programas com formato, conteúdo e linguagem acadêmica. Sabe-se, contudo, que as emissoras, principalmente as de rádio, transmitindo em sinal aberto, têm audiência potencial entre variadas camadas da população e poderiam, como prevê a legislação, colaborar para atender às necessidades educativas básicas e permanentes da comunidade na qual está inserida. Foi com essa preocupação que formatamos a grade de programação da Veritas FM.

Uma emissora educativa compartilha os mesmos espaços com as emissoras comerciais. Nos espaços midiáticos comerciais no Brasil, tradicionalmente, trafega a cultura de massa. A definição oferecida por Muniz Sodré demonstra as forças que operam esse sistema:

A cultura de massa - frisamos: essencialmente política - é hoje o grande medium da atmosfera capitalista. No caso brasileiro, ela é também o espelho que reflete $\mathrm{o}$ id e os demônios das nossas estruturas. É o espelho em que a sociedade se olha e se oferece como espetáculo².

Apesar de seu caráter público, os veículos de comunicação tornaram-se verdadeiras capitanias hereditárias em nosso país, preocupados, apenas, em atrair a qualquer custo a audiência massiva para suas programações. As duas grandes forças, a política e a econômica, em geral, não apóiam as emissoras educativas nem comungam dos mesmos interesses que elas. A emissora educativa é vista como uma concorrente pelas emissoras comerciais, já que rouba o seu melhor capital: os ouvintes.

\section{AS FMs COMERCIAIS, A REALIDADE REGIONAL E OS PARADIGMAS CULTURAIS}

A programação das emissoras radiofônicas em Bauru, resultante de um processo que abordaremos no próximo parágrafo, é semelhante à existente em grande parte dos pequenos e médios municípios brasileiros. O fato é que as emissoras de rádio FM comerciais condicionaram-se a oferecer e condicionam seus ouvintes a consumir, basicamente, entretenimento e recreação. Notícias, em geral pautadas pelos jornais regionais impressos, são bem-vindas em horários regulares. A programação é composta de músicas selecionadas pela indústria fonográfica, que objetiva consolidar o repertório musical dos

2. SODRÉ, M. A comunicação do grotesco. Petrópolis: Vozes, 1972. p. 39 ouvintes, levando-os a desejarem os produtos que ofertam. Existem, ainda, algumas opções de entretenimento, quadros de humor, gincanas e fofocas. 
Intencionalidade educativa em freqüência modulada • Lígia Beatriz C. de Almeida

O ouvinte, em alguns momentos, é convidado a participar pedindo e oferecendo músicas.

Muniz Sodré sugere que "cultura é, na verdade, um sistema mediador - uma espécie de circuito que possibilita a circulação, a análise e a cons-

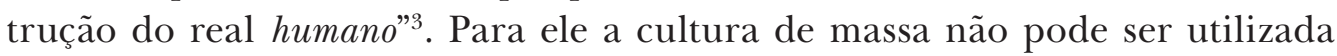
em oposição à cultura superior, considerando que ambas utilizam o mesmo código, com a diferença de que nas mensagens de massa o código "tem de se tornar mais pobre para aumentar o índice de percepção por parte dos receptores", posto que serão inseridas em uma "sociedade capitalista por seu caráter industrial: é a cultura que se vende, a cultura de mercado [...] com características transnacionais em vários aspectos" ${ }^{\circ}$. A partir desses conceitos vamos observar quais bens culturais, quais valores circulam e são valorizados por produtor e consumidor na programação das emissoras de rádio comerciais. A mídia utiliza uma referência circular. Para construir o real humano, sugerido por Sodré, ela tira da sociedade seus interesses e devolve esses mesmos interesses para a sociedade sob a forma de programas. Buscando traços desses interesses na programação das emissoras, constata-se que a mídia comercial radiofônica nivela-os por baixo, operando cômoda e minimamente, com reduzidíssimos temas dentre os que integram os interesses e necessidades diários do cidadão. Poder-se-ia justificar que se trata de um hábito sedimentado por intermédio do modelo econômico que passou a sustentar o veículo desde a introdução, no Brasil, da devoradora das verbas publicitárias - a televisão -, que, ao reduzir as verbas para a mídia radiofônica, terminou reduzindo seus talentos produtivos; o que, por sua vez, acarretou na pouca diversidade do conteúdo, na nivelação das expectativas da audiência e na cristalização dos hábitos de audiência como se apresentam. Hoje, não mais se questiona o fazer ou o ouvir. O paradigma está consolidado: a rádio comercial é como é e não se discute. A cultura radiofônica está, nesse padrão, integrada à vida do cidadão. Conclui-se que, apesar de mais de três décadas nos separarem da afirmação feita por Muniz Sodré, de que "todo o aparato tecnológico da comunicação brasileira tem sido acionado até agora por uma política de manutenção de um sistema de inércias, perfeitamente ajustado ao interesse de forçar o consumo" ${ }^{6}$, nada se alterou no cenário midiático brasileiro. As emissoras de rádio continuam fiéis aos paradigmas culturais alienantes e imobilistas.

Em face de tal paradigma, resvala-se em forte resistência à audição de programas com intencionalidade socioeducativa, notadamente entre os ouvintes de rádio FM. E vale ressaltar que, hoje, a maioria dos ouvintes sintoniza seu rádio em freqüência modulada. Nossos jovens, em grande parte, desconhecem a existência da sintonia AM em seus aparelhos receptores.

É interessante observar que o hábito de audiência mencionado apresenta repercussão em todo o eixo produtivo, como poderemos constatar em parágrafos subseqüentes.

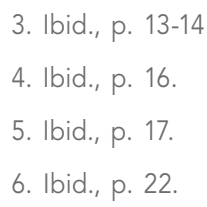


comunicação \& educação • Ano XIII • Número 1 • jan/abr 2008

\section{ESTRATÉGIAS INICIAIS}

A Rádio Veritas FM é uma emissora educativa vinculada à Fundação Veritas, situada no Campus da Universidade do Sagrado Coração, em Bauru-SP. Em 2002, após operar em caráter experimental pelo período de seis meses, começou a delinear sua identidade. Nesse momento, no município atuavam quatro emissoras FM: duas comerciais, uma religiosa e uma educativa, vinculada à Universidade Estadual de São Paulo.

Por definição de sua coordenação e tendo como norte a natureza educativa, a emissora deveria posicionar-se como uma opção em programação, sem assumir postura concorrente com qualquer outra emissora existente no mercado. Para servir de complemento à programação oferecida pela outra rádio educativa FM da cidade, cuja programação era voltada para uma classe mais elitizada, a Veritas definiu como seu público-alvo os jovens e adultos das classes mais populares.

Três etapas deveriam ser percorridas para alcançar o percentual desejado de projetos educacionais. O primeiro momento seria destinado a contratar e treinar a equipe, consolidar a programação diária, organizar o acervo musical, enfim, criar uma identidade para a emissora. A segunda etapa envolvia a criação de estratégias que levassem ao envolvimento da comunidade, o que foi feito por meio de diversas promoções, concursos culturais e participação em eventos. Ao final da segunda etapa começamos a introdução de mensagens educativas com caráter mais formal. Em um terceiro momento o objetivo seria a inserção de programas com maior formalidade educativa e com incentivo ao envolvimento mais sistemático da comunidade no eixo produtivo.

Pearce ${ }^{7}$, propondo novos modelos e metáforas comunicacionais, ressalta que o contexto em que nos encontramos prefigura como devemos atuar no construcionismo social. Em sua teoria de comunicação, ele define duas forças: a contextual (representada pelo contexto vigente) e a implicativa (caracterizada pela ação realizada e suas conseqüências sobre o contexto). Pois bem, em nosso projeto analisamos o contexto e delineamos forças implicativas que pudessem gerar transformações. $\mathrm{O}$ contexto apontava para uma audiência habituada a sintonizar as emissoras comerciais e o desafio consistia em conquistá-la, em propor gradualmente a quebra do paradigma da cultura de massa, apresentan-

7. PEARCE, W. B. Novos modelos e metáforas comunicacionais: a passagem da teoria à prática, do objetivismo ao constricionismo social e da representação à reflexividade. In: SCHNITMAN, D F. (Org.). Novos paradigmas, cultura e subjetividade. Porto Alegre: Artes Médicas, 1996. do um novo conceito em programação que permitisse a inserção de conceitos educativos.

Em um primeiro momento, para a conquista desses ouvintes adotou-se um formato estético composto de vinhetas, chamadas e locução semelhantes às utilizadas pelas emissoras comerciais, evitando-se causar o estranhamento, normalmente atribuído às emissoras educativas. Conquistava-se pela aparência e introduziam-se conceitos educativos ao longo de toda a programação. 


\section{A EQUIPE E A PROGRAMAÇÃO DA VERITAS FM}

A coordenação da emissora procurou estimular projetos de extensão de discentes, principalmente daqueles que se dedicam ao estudo das Ciências Sociais Aplicadas. Como resultado, algumas propostas foram formalizadas por eles. A onipotência da formação cultural imposta pelas mídias comerciais de massa evidenciava-se nas propostas recebidas, noventa por cento delas direcionadas à produção de programas musicais, ignorando a possibilidade de produção de mensagens com intencionalidade educativa. Destas, quase nenhuma contemplava a integração de conteúdos socioeducativos. Foi necessário um trabalho de conscientização e estimulação para que esses conceitos passassem a ser valorizados pelos produtores e inseridos nos programas.

Dificuldade semelhante foi encontrada no quadro de funcionários. Muitas empresas preferem recrutar funcionários sem experiência para moldá-los às suas necessidades. Isso é um grande desafio quando consideramos o contexto educativo brasileiro. Mesmo sem experiência profissional, qualquer cidadão é fruto da cultura capitalista na qual cresceu e já é um ouvinte permeado pelos conceitos difundidos pela rádio comercial. A Veritas FM, consciente de que precisaria se dedicar ao treinamento da equipe de trabalho, buscou talentos que atuavam no mercado comercial. Essa opção foi orientada pelo desejo de trabalhar com profissionais que trouxessem identificação com as emissoras comerciais e que usassem linguagem jovem. Ao chegarem à emissora, os problemas vinham à tona: começavam pelas vinhetas elaboradas por eles, que tendiam a apresentar afirmações clichês como "a melhor emissora do seu dial", "só aqui você ouve o melhor da música", e se refletiam no discurso fundado na busca pela audiência quantitativa em detrimento da qualitativa: "Temos que tocar tais músicos, se quisermos conquistar a audiência”. Percebia-se a frustração quando argumentávamos que para sermos uma opção à programação comercial teríamos de abdicar dos índices de audiências e apostar em captação de audiência em médio prazo.

Conscientes de que a mudança de hábito seria obtida de forma gradual, já que contávamos com uma audiência não comprometida com os objetivos da emissora, em um primeiro momento, optamos pela produção e inserção de programetes de cunho socioeducativo em toda a programação. Legislação, previdência social, dicas para o consumo consciente, preservação do meio ambiente, sugestão de leituras, filmes e atividades culturais passaram a compor o intervalo dos programas de entretenimento. O recém-contratado programador, um profissional com anos de atuação em emissoras comerciais, encarou o desafio de aprender a lógica invertida em nossa realidade educativa: o programete veiculado no intervalo dos programas de entretenimento é mais importante que o programa no qual ele se insere; portanto, não pode falhar, nem ser substituído por música, tendo o mesmo valor que a inserção da chamada de um cliente na rádio comercial. 
comunicação \& educação • Ano XIII • Número 1 • jan/abr 2008

Outras polêmicas permeavam as reuniões de programação - como ter qualidade sem elitizar? Como aferir a qualidade musical? E o equacionamento sempre considerava o objetivo-fim da emissora: entre cada bloco de música, motivar o ouvinte à reflexão sobre sua qualidade de vida e subsidiá-lo com informações que pudessem culminar em transformações positivas. O potencial educativo de um veículo de comunicação de massa deve ser destinado a todas as camadas sociais, sem discriminar faixa etária nem classe social. Como a música era o atrativo do público-alvo, optou-se por uma diversidade musical, com baixos índices de repetição, excluindo-se apenas letras que induzissem a atitudes anti-sociais (exploração do sexo inconseqüente, uso de drogas, discriminação racial e palavrões). Essa atitude suscitou polêmica e fez com que fôssemos alvos de crítica por parte da comunidade acadêmica, a qual não entendia como uma rádio educativa abria espaço para um programa como o cultura pop, destinado a um acéfalo público adolescente situado nas classes sociais C e D. Apostávamos que nossos drops educativos chegariam até eles.

\section{ONDE ESTÁ O OUVINTE?}

Um outro aspecto a ser considerado, e que também é reflexo do hábito de ter permanecido durante anos simplesmente como receptor de mensagens, é a postura passiva do ouvinte brasileiro. Quase nenhuma participação acontece de forma espontânea. O ouvinte provocado a se manifestar quase não o faz, a menos que lhe seja oferecida uma compensação material. A maior parte dos e-mails e das ligações recebidas repousava em interesses individuais, solicitando músicas ou ingressos sorteados para shows ou peças de teatro. Essa postura é extensiva aos programas informativos e educativos regularmente veiculados. A veiculação de programas com intencionalidade socioeducativa mais formal, como os jornalísticos (Jornal Brasil Hoje, Revista Bauru), ou aqueles que abordaram os ícones da literatura brasileira (Na Janela), o uso de técnicas educativas (Educação Plugada), a análise de temas, por meio da interpretação de letras musicais (Uma música, um tema), a questão da solidariedade (Onda Solidária), ou ainda uma revista de recortes, como é o caso do Sintonia Sesc Senac, têm a sua audiência comprovada por depoimentos pessoais e por poucos e-mails recebidos. Em alguns momentos, para motivar o ouvinte a responder, criávamos formas interativas nos programas gravados, com concursos culturais. A forma usual para avaliar a satisfação do ouvinte seria a aplicação de pesquisas qualitativas, alternativa inviável devido ao alto custo operacional.

A programação da Veritas FM caminhava na contramão da globalização. Os produtos nacionais eram privilegiados, abria-se espaço para manifestações culturais regionais e locais. O padrão de locução utilizado era desvinculado de imposições estéticas e a voz comum era explorada, tendo-se o cuidado necessário com dicção e entonação. Mas isso não implicava ignorar o que ocorria na esfera mundial: a música latina e a internacional estavam presentes. O jornalismo 
Intencionalidade educativa em freqüência modulada • Lígia Beatriz C. de Almeida

diário, ao configurar-se como opção e complemento ao que é oferecido por outras emissoras, retratava acontecimentos internacionais e nacionais.

Como não se dispunha de verba para pesquisa, os indícios de aprovação da programação espontaneamente obtidos eram altamente motivadores. $\mathrm{O}$ assédio de investidores, interessados na veiculação de mensagens comerciais, também era um forte sinal de aceitação da emissora no cotidiano da comunidade.

\section{CONSIDERAÇÕES FINAIS}

O cenário traçado foi, para mim, positivo, motivador e inovador: promovia a revisão de conceitos e apontava para o desenho de estratégias criativas que convergissem para um denominador comum entre os interesses públicos e educativos.

Dedicar-se a um projeto educativo em um ambiente midiático estritamente comercial requer boa dose de utopia. É preciso acreditar nas transformações e que é possível desenvolver estratégias capazes de sensibilizar mentes subjugadas por paradigmas entranhados.

Ainda que a mudança cultural constitua um fenômeno social que ocorre de forma vagarosa, sabemos que as informações diferenciadas, veiculadas diariamente nas mídias de massa, são um modelo a ser seguido por outras emissoras; assim, elevam-se as expectativas da população, faz-se com que conceitos e posturas sejam revistos e fomenta-se, inclusive, a formação de consciência cidadã por meio do envolvimento da sociedade no eixo produtivo. Quando esse envolvimento se tornar realidade, estará mais próxima a possibilidade de que seja oferecido ao público não mais o que se pressupõe que ele precise, mas sim o que a comunidade indique como sendo relevante à discussão. Aí sim será alcançado o objetivo educativo na mídia.

De imediato, superar as dificuldades pode ser mais fácil ampliando-se as discussões a respeito da potencialidade educativa e estimulando-se a troca de idéias entre as emissoras sobre formatos e gêneros de programação, bem como se engendrando uma rede de permuta de produtos midiáticos, o que aumentaria a oferta de programas diversificados em cada região, sem onerar a capacidade produtiva das emissoras e disseminando novas idéias pelo cruzamento de informações e oxigenando o setor produtivo.

No momento em que terminava minhas reflexões, diversas evidências sinalizavam para o correto delineamento de estratégias. O programa Educação Plugada havia concorrido e figurava entre os finalistas do Prêmio IGE de Jornalismo, que tem por objetivo, entre outros, estimular a cobertura jornalística sobre a educação formal, básica e pública no Brasil. A Veritas FM, pequena emissora regional educativa, concorreu com emissoras de peso no cenário nacional. $\mathrm{O}$ programa foi considerado uma das três melhores iniciativas inovadoras no Brasil. Dar voz a professores e pesquisadores para, fazendo uso da linguagem e da mídia radiofônica, falar a seus pares, proporcionando oportunidades para trocas de idéias e reflexão, é uma iniciativa inovadora? A meu ver, o grande 
mérito não estava na fórmula do programa e muito menos no conteúdo, mas sim na ousadia de levar a sério uma iniciativa que cumpria nada mais do que os objetivos previstos em legislação para a radiodifusão educativa.

Porém, a palavra final permaneceu com a lógica política e capitalista, a qual permite que outros interesses se sobreponham a iniciativas como esta, e a terceira etapa de nosso projeto não pôde ser implantada em decorrência da redução de verbas para a emissora.

Resumo: $O$ artigo mostra quem pode pleitear permissão para gerir as emissoras educativas no Brasil, qual a natureza do conteúdo a ser veiculado, quais atores dominam as emissões radiofônicas em freqüência modulada e que paradigmas permeiam a relação ouvinte/emissora FM. Na seqüência, é relatada a experiência da autora como coordenadora de programação de uma emissora regional FM educativa, na qual pôde delinear a linha de programação, selecionar e treinar os primeiros colaboradores e formatar projetos de extensão. As dificuldades encontradas mostram que, apesar do contexto, é possível veicular conceitos os quais privilegiem os interesses públicos e sociais, captando e mantendo a audiência de diversas camadas sociais. Finalmente, a conclusão aponta para as forças político-financeiras, que dominam o cenário midiático brasileiro, como sendo os principais entraves ao desenvolvimento de uma mídia educativa e cidadã.

Palavras-chave: rádio educativa, paradigma cultural, programação radiofônica, rádio FM, mídia regional.
Abstract: This article describes those who can apply for a permission to administrate Brazilian educative radio stations, the contents to be broadcasted, which actors control the FM band and the paradigms present in the relationship between the listener and the FM station. Is related the experience of author as a programming coordinator in a regional educative FM radio station, showing how the programming profile was defined, which were the criterions to hire the employees and their training processes, how extension projects were designed. The experience reveals that is possible to please the audience and make the programming meet the educational needs of the public. Political and financial interests in Brazil manipulating the medium are responsible for blocking the development of public broadcasting and the citizen's needs for educational programs.

Keywords: educative radio, cultural paradigm, radio programming, FM radio, regional media. 